\title{
Estudo das poliaminas na morfogênese in vitro de Hemerocallis sp.
}

\author{
Study of polyamines in the morphogenesis in vitro of Hemerocallis sp.
}

\author{
Clayton Debiasi ${ }^{I}$ Chrystiane Borges Fráguas ${ }^{\mathrm{I}}$ \\ Giuseppina Pace Pereira Lima'
}

\section{RESUMO}

Em cultura de tecidos, ações de indução do desenvolvimento vegetal e também controle oxidativo de células e tecidos, podem ser atribuidas às poliaminas. Neste sentido, propôs-se investigar a participação das poliaminas espermidina (SPD), espermina (SPM) e putrescina (PUT) na indução da diferenciação de calos e no controle oxidativo de células e tecidos de Hemerocallis sp cultivados in vitro. Massas celulares, oriundas de calos produzidos in vitro, foram cultivadas em meio de cultura MS, suplementado com SPD, SPM e PUT em diferentes concentrações e combinações, avaliando-se teores endógenos de poliaminas e proteinas solúveis, atividade das peroxidases (EC 1.11.1.7), número e altura dos brotos, porcentagem de microbrotações, hiperhidricidade e necrose, e formação de calos. Os resultados apontam uma participação das poliaminas não só na indução da morfogênese, mas também no que se refere aos padrões oxidativos de células e tecidos. Ao final do experimento, a aplicação de PUT, isolada

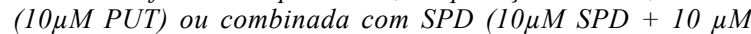

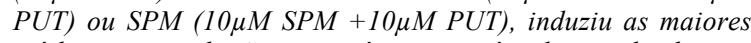
médias em relação ao número e à altura de brotos diferenciados. Já a combinação das três poliaminas no meio de cultura $(10 \mu M S P D+10 \mu M S P M+10 \mu M P U T)$ induziu maior porcentagem (60\%) de formação de microplantas nos calos. A combinação de SPD e SPM $(10 \mu M S P D+10 \mu M$ $S P M)$ induziu maior quantidade de tecido necrosado (65\%). Verificou-se que SPM aplicada exogenamente no meio de cultura (10 $\mu M$ SPM) pode atuar como antioxidante celular na cultura de calos desta espécie.

Palavras-chave: espermidina, espermina, putrescina, antioxidante, cultura de tecidos.

\section{ABSTRACT}

In tissue culture, the action of induction of the vegetal development and also oxidative control of cells and tissues are attributed to the polyamines. This study was aimed at verifing the participation of the polyamines spermidine $(S P D)$, spermine (SPM) and putrescine (PUT) in the induction of callus differentiation and in the oxidative control at Hemerocallis sp. cultivated in vitro. Cell mass produced by callus in vitro were cultivated in medium MS, supplemented with SPD, SPM and PUT in different concentrations and combinations, by evaluating endogenous contents of polyamines and soluble proteins, and peroxidase activity (EC
1.11.1.7), number and height of shoots, hyperhydricity and necrosis, and formation of calluses. The results indicate that polyamines participate not only at the morphogenesis induction, but also to the oxidative standards of cells and tissues. At the end of the study PUT, isolated $(10 \mu M$ PUT) or with SPD $(10 \mu M$ $10 S P D+10 \mu M$ PUT) or SPM (10 $\mu M S P M+10 \mu M P U T)$, induced the biggest average related to number and height of differentiated shoots. Already the combination of the three polyamines in the medium $(10 \mu M S P D+10 \mu M S P M+10 \mu M$ $P U T)$ induced mayor parts (60\%) of micro shoots in the callus. The SPD and SPM combination $(10 \mu M S P D+10 \mu M S P M)$ induced the biggest quantity of necrosis tissue (65\%). It was verified that SPM, applied exogenously in the medium (10 $\mu M$ SPM) can act as antioxidant in the tissue culture of this species.

Key words: spermidine, spermine, putrescine, antioxidant, tissue culture.

\section{INTRODUÇÃO}

Em cultura de tecidos, as poliaminas vêm sendo utilizadas como reguladores vegetais, buscando-se sempre obter diversos tipos de respostas, tais como embriogênese (YADAV \& RAJAM, 1997), enraizamento (RUGINI, 1992), formação de prococormos (SAIPRASAD et al., 2004), entre outros.

Além de as poliaminas demonstrarem efeitos durante os eventos organogenéticos (TANG et al., 2004), são atribuídos a estas substâncias efeitos antioxidantes, exercendo proteção às células, incluindo membranas, ácidos nucléicos e ácidos graxos polinsaturados de danos oxidativos (LOVAAS, 1997). Segundo LOVAAS (1997), as poliaminas atuam como quelantes de metais, diminuindo sua ação oxidativa nas células.

A oxidação de tecidos vegetais cultivados in vitro é um fenômeno observado em diversas espécies, ocorrendo também com freqüência em calos (TANG et al., 2004). Foi relatado que a peroxidase (EC 1.11.1.7) apresenta alterações na atividade em tecidos

'Departamento de Química e Bioquímica, Instituto de Biociências (IB), Universidade Estadual Paulista (UNESP), CP 510, 18618000, Botucatu, SP, Brasil. E-mail: gpplima@ibb.unesp.br. Autor para correspondência. 
que mostram algum tipo de escurecimento (LAUKKANEN et al., 2000). Já as poliaminas exercem efeito protetor e, quando usadas exogenamente, tendem a induzir menor taxa de oxidação, promovendo uma diminuição na atividade da peroxidase (TANG et al., 2004).

Baseados nas descrições dos efeitos das poliaminas sobre o crescimento e desenvolvimento vegetal, cabem estudos que integrem estas informações a princípios básicos de diferenciação de tecidos e ainda que interajam os processos indutivos com outras substâncias que controlam a fisiologia do desenvolvimento. Neste sentido é que o presente estudo se propôs a investigar a participação das poliaminas espermidina, espermina e putrescina na indução da diferenciação in vitro de calos de Hemerocallis $\mathrm{sp}$, assim como o seu possível efeito antioxidante.

\section{MATERIAL E MÉTODOS}

A partir de segmentos de $2 \mathrm{~mm}$ de escapes florais de Hemerocallis sp., cultivados por 45 dias em meio de cultura Murashige \& Skoog (1962) (MS), suplementado com $30 \mathrm{~g} \mathrm{~L}^{-1}$ de sacarose, $100 \mathrm{mg} \mathrm{L}^{-1}$ de inositol, $100 \mathrm{mg} \mathrm{L}^{-1}$ de caseína, $1 \mathrm{mg} \mathrm{L}^{-1}$ de cinetina (KIN), $5 \mathrm{mg} \mathrm{L}^{-1}$ de ácido 2,4-diclorofenóxiacético $(2,4 \mathrm{D})$ e $7 \mathrm{~g} \mathrm{~L}^{-1}$ de ágar-ágar, foram produzidos os calos utilizados no experimento. Alíquotas de $1 \mathrm{~g}$ de massa celular dos calos foram cultivadas, por mais 45 dias, em meio de cultura MS suplementado com $30 \mathrm{~g} \mathrm{~L}^{-1}$ de sacarose, $7 \mathrm{~g} \mathrm{~L}^{-1}$ de ágar-ágar e as poliaminas espermidina (SPD), espermina (SPM) e putrescina (PUT), em diferentes combinações e concentrações ( T1 - controle; T2 - 10 $\mu \mathrm{M}$ SPD; T3 $10 \mu \mathrm{M}$ SPM; T4 - 10 $\mu \mathrm{M}$ PUT; T5 - 10 $\mu \mathrm{M}$ SPD $+10 \mu \mathrm{M}$

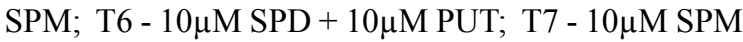
$+10 \mu \mathrm{M}$ PUT; T8 $-10 \mu \mathrm{M}$ SPD $+10 \mu \mathrm{M} \mathrm{SPM}+10 \mu \mathrm{M}$ PUT) (90 dias de cultivo). Após este período, os calos tratados com poliaminas foram transferidos para cultivo em meio de cultura MS suplementado com $30 \mathrm{~g} \mathrm{~L}^{-1} \mathrm{de}$ sacarose e $7 \mathrm{~g} \mathrm{~L}^{-1}$ de ágar-ágar por 45 dias (135 dias de cultivo), ausente de poliaminas, quando avaliou-se os teores de poliaminas endógenos, teor de proteínas totais solúveis e a atividade das peroxidases (EC 1.11.1.7), além de avaliações biométricas, tais como número (contagem de plantas) e altura dos brotos formados (medida em $\mathrm{cm}$ ), porcentagem de microbrotações, porcentagem de hiperhidricidade (contagem de plantas visualmente, com aspecto hiperhídrico) e porcentagem de calos (contagem de calos formados), sendo que as porcentagens foram obtidas a partir do número de microbrotações, calos e hiperdricidade formadas ou aparentes, descontado de $100 \%$ do total. A hiperhidricidade foi analisada tendo como base o aspecto translúcido que ocorre em massa de calos e partes de plantas, que apresentam aspecto vítreo, devido ao elevado teor de água em suas células e tecidos. Parte do material foi transferida para meio similar, porém sem o agente geleificante e sob agitação (100rpm), e após 30 dias (165 dias de cultivo), foram realizadas análises bioquímicas e biométricas similares às descritas anteriormente.

O experimento foi mantido em sala de crescimento sob fotoperíodo de 16 horas de luz (intensidade luminosa de $50 \mu \mathrm{mol} \mathrm{m} \mathrm{m}^{2} \mathrm{~s}^{-1}$ )/8 horas de escuro e temperatura média de $27 \pm 1^{\circ} \mathrm{C}$, totalizando 165 dias de cultivo. O delineamento utilizado foi inteiramente ao acaso, contendo oito tratamentos e dez repetições, sendo os resultados analisados mediante ANOVA e teste de separação de médias Tukey 5\%.

Análises bioquímicas

As análises dos teores de poliaminas foram realizadas de acordo com o método proposto por FLORES \& GALSTON (1982), modificado por LIMA et al. (2006).

As análises da atividade da peroxidase (EC 1.11.1.7) foram realizadas de acordo com método descrito por LIMA et al. (1999). Sobrenadantes (extrato bruto) foram obtidos a partir da homogeneização de amostras de tecido fresco em tampão fosfato $0,2 \mathrm{M} \mathrm{pH}$ 6,7 gelado e centrifugados a $4^{\circ} \mathrm{C}$. Foram utilizados, para determinação da atividade, $20 \mathrm{mM}$ de peróxido de hidrogênio, $4 \mathrm{mM}$ de aminoantipirina e $10 \mathrm{mM}$ de fenol, sendo os resultados expressos em (mol de $\mathrm{H}_{2} \mathrm{O}_{2}$ decomposto $\mathrm{g}^{-1} \mathrm{~min}^{-1}$

Os teores de proteínas totais solúveis foram determinados de acordo com o método descrito por BRADFORD (1976).

\section{RESULTADOS E DISCUSSÃO}

Os resultados apontam para uma participação direta das poliaminas no comportamento in vitro de Hemerocallis sp., uma vez que estas substâncias parecem atuar não só na indução e no controle da morfogênese, mas também no que se refere aos padrões oxidativos de células e tecidos. Estas constatações encontram respaldo na literatura, uma vez que várias rotas morfogenéticas (SAIPRASAD et al., 2004; DAVIS \& OLSON, 1994) e controles oxidativos (TANG et al., 2004) foram associados ao efeito direto de alguma poliamina suplementada ao meio de cultura durante o cultivo in vitro de diferentes espécies.

$\mathrm{Na}$ tabela 1, são apresentados resultados referentes a características biométricas observadas após tratamento dos calos com poliaminas, aos 135 dias de cultivo. Quanto ao efeito das poliaminas sobre número de brotações, apenas PUT aplicada isoladamente (T4) mostrou resultado semelhante ao 
Tabela 1 - Características biométricas avaliadas em material de Hemerocallis sp. submetido anteriormente a tratamentos com poliaminas $(\mathrm{T} 1=$ isento de poliaminas, T2 $=10 \mu \mathrm{mol} \mathrm{g} \mathrm{mf}^{-1} \mathrm{SPD}, \mathrm{T} 3=10 \mu \mathrm{mol} \mathrm{g} \mathrm{mf}^{-1} \mathrm{SPM}, \mathrm{T} 4=10 \mu \mathrm{mol} \mathrm{g} \mathrm{mf}^{-1} \mathrm{PUT}$, T5 $=10 \mu \mathrm{mol} \mathrm{g} \mathrm{mf}^{-1} \mathrm{SPD}+10 \mu \mathrm{mol} \mathrm{g} \mathrm{mf}{ }^{-1} \mathrm{SPM}$, T6=10 $\mu \mathrm{mol} \mathrm{g} \mathrm{mf}{ }^{-1}$ SPD $+10 \mu \mathrm{mol} \mathrm{g} \mathrm{mf}^{-1}$ PUT, T7 $=10 \mu \mathrm{mol} \mathrm{g} \mathrm{mf}^{-1} \mathrm{SPM}+10 \mu \mathrm{mol} \mathrm{g} \mathrm{mf}{ }^{-1}$ PUT, T8=10 $\mu \mathrm{mol} \mathrm{g} \mathrm{mf}^{-1} \mathrm{SPD}+10 \mu \mathrm{mol} \mathrm{g} \mathrm{mf}^{-1} \mathrm{SPM}+10$ $\mu \mathrm{mol} \mathrm{g} \mathrm{mf}^{-1}$ PUT) e cultivado em meio de cultura MS por 135 dias de cultivo e em meio de cultura MS sob agitação (100 rpm) por 165 dias de cultivo.

\begin{tabular}{|c|c|c|c|c|c|c|c|c|}
\hline \multirow[b]{2}{*}{ Tratamentos } & \multicolumn{8}{|c|}{135 dias de cultivo } \\
\hline & $\mathrm{T} 1$ & $\mathrm{~T} 2$ & $\mathrm{~T} 3$ & $\mathrm{~T} 4$ & T5 & $\mathrm{T} 6$ & $\mathrm{~T} 7$ & $\mathrm{~T} 8$ \\
\hline $\mathrm{N}^{\circ}$ de brotos & $4,30 \mathrm{a}$ & $2,00 \mathrm{~b}$ & $2,10 \mathrm{~b}$ & $4,00 \mathrm{a}$ & - & $0,40 \mathrm{de}$ & $1,60 \mathrm{bc}$ & $1,00 \mathrm{~cd}$ \\
\hline Altura (cm) & $1,75 \mathrm{ab}$ & $1,30 \mathrm{~b}$ & $2,35 \mathrm{a}$ & $2,35 \mathrm{a}$ & - & $0,40 \mathrm{c}$ & $1,50 \mathrm{~b}$ & $1,80 \mathrm{ab}$ \\
\hline \% Microbrotações & $74,00 \mathrm{a}$ & $73,00 \mathrm{a}$ & $38,00 \mathrm{bc}$ & $54,50 \mathrm{abc}$ & - & $36,50 \mathrm{c}$ & $64,50 \mathrm{ab}$ & $76,50 \mathrm{a}$ \\
\hline$\%$ Hiperhidricidade & $79,50 \mathrm{abc}$ & $65,00 \mathrm{~cd}$ & $88,50 \mathrm{ab}$ & $72,50 \mathrm{bca}$ & 77,50abcd & $55,50 \mathrm{~d}$ & $95,50 \mathrm{a}$ & $75,50 \mathrm{abcd}$ \\
\hline \multirow[t]{2}{*}{$\%$ Calo } & $26,00 \mathrm{~d}$ & $27,00 \mathrm{~d}$ & $62,00 \mathrm{bc}$ & $45,50 \mathrm{bca}$ & $100,00 \mathrm{a}$ & $63,50 \mathrm{~b}$ & $35,50 \mathrm{~cd}$ & $23,50 \mathrm{~d}$ \\
\hline & \multicolumn{8}{|c|}{165 dias de cultivo } \\
\hline Tratamentos & $\mathrm{T} 1$ & $\mathrm{~T} 2$ & $\mathrm{~T} 3$ & $\mathrm{~T} 4$ & $\mathrm{~T} 5$ & T6 & $\mathrm{T} 7$ & $\mathrm{~T} 8$ \\
\hline $\mathrm{N}^{\circ}$ de brotos & $17,80 \mathrm{a}$ & $2,60 \mathrm{c}$ & $3,00 \mathrm{c}$ & $22,10 \mathrm{a}$ & $2,40 \mathrm{c}$ & $6,60 \mathrm{bc}$ & $10,10 \mathrm{~b}$ & $4,00 \mathrm{c}$ \\
\hline Altura dos brotos $(\mathrm{cm})$ & $3,05 \mathrm{a}$ & $1,32 \mathrm{~b}$ & $2,50 \mathrm{ab}$ & 3,09 a & $1,15 \mathrm{~b}$ & $3,30 \mathrm{a}$ & $3,31 \mathrm{a}$ & $3,70 \mathrm{a}$ \\
\hline $\mathrm{N}^{0}$ de raízes & $0,50 \mathrm{a}$ & - & - & $1,10 \mathrm{a}$ & - & $0,90 \mathrm{a}$ & $0,30 \mathrm{a}$ & - \\
\hline Comprimento raízes $(\mathrm{cm})$ & $0,20 \mathrm{a}$ & - & - & $0,60 \mathrm{a}$ & - & $0,65 \mathrm{a}$ & $0,30 \mathrm{a}$ & - \\
\hline$\%$ Calos & $51,00 \mathrm{~b}$ & $88,00 \mathrm{a}$ & $75,50 \mathrm{a}$ & $36,20 \mathrm{bc}$ & $85,00 \mathrm{a}$ & $39,00 \mathrm{bc}$ & $25,60 \mathrm{~cd}$ & $10,00 \mathrm{~d}$ \\
\hline$\%$ Microplantas & $21,70 \mathrm{~b}$ & $14,40 \mathrm{~b}$ & $25,00 \mathrm{~b}$ & $30,00 \mathrm{~b}$ & $15,00 \mathrm{~b}$ & $28,00 \mathrm{~b}$ & $26,20 \mathrm{~b}$ & $60,00 \mathrm{a}$ \\
\hline$\%$ Hiperhidricidade & $4,95 \mathrm{a}$ & - & - & $3,97 \mathrm{a}$ & - & $5,10 \mathrm{a}$ & - & - \\
\hline$\%$ Necrose & $2,00 \mathrm{c}$ & $14,00 \mathrm{c}$ & $7,50 \mathrm{c}$ & $12,30 \mathrm{c}$ & $65,00 \mathrm{a}$ & $31,40 \mathrm{~b}$ & - & - \\
\hline
\end{tabular}

Letras que se diferenciam na horizontal indicam diferença significativa entre as médias pelo teste Tukey $5 \%(\mathrm{~N}=10)$.

controle. Já em relação à altura das brotações formadas nos calos com 135 dias após o início do cultivo, tanto PUT, como SPM, foram eficazes em promover maior crescimento em altura, porém não diferenciaram significativamente do controle. Neste período, não foi observada a formação de brotos no tratamento contendo a combinação de SPD e SPM (T5). A aplicação das três poliaminas combinadas (T8) induziu a maior porcentagem de microbrotações. SPM isolada (T3) ou em combinação com PUT (T7) induziu a maior porcentagem de calos hiperhídricos, enquanto que a combinação de SPD e SPM (T5) mostrou ser bom indutor de calos em Hemerocallis.

Em todos os tratamentos, foram observadas porções do calo sem diferenciação, ou seja, não apresentavam sinais de formação de órgãos. Aos 165 dias, nos tratamentos contendo SPD e SPM isoladas (T2 e T3) ou combinadas (T5), foram observadas as maiores porções de calos intactos, isto é, sem regeneração, $88,75,5$ e $85 \%$ respectivamente. Por outro lado, o tratamento contendo a combinação das três poliaminas (T8) apresentou a menor porção, apenas $10 \%$, mostrando maior regeneração.

Em relação às características biométricas observadas nos calos após 30 dias em meio líquido sob agitação (165 dias de cultivo), ocorreu tendência semelhante quanto ao número de brotos e altura, onde a aplicação de PUT (T4) induziu as maiores médias. Nos tratamentos contendo SPD e SPM isoladas (T2 e T3) ou combinadas entre si (T5) ou com PUT (T8), não foram observadas formações de raízes. A combinação das três poliaminas no meio de cultura (T8) induziu a formação de microplantas em maior número $(60 \%)$. Nesta etapa experimental, PUT exógena aplicada isolada (T4) ou combinada com SPD (T6) induziu a hiperhidricidade dos calos, semelhantemente ao encontrado no controle (T1). SPD e/ou SPM (T2 e T3) induziram formação da maior porcentagem de calos, porém, quando combinada com PUT (T6, T7 e T8), essa taxa foi baixa. A combinação de SPD e SPM (T5) também induziu a maior quantidade de tecido necrosado $(65 \%)$ neste período de observação.

Para correlacionar poliaminas com diferentes etapas do desenvolvimento, foram determinados os teores de poliaminas livres nos diferentes tecidos e períodos de cultivo, conforme apresentados na tabela 2. Baixos valores das três poliaminas foram encontrados na análise do controle aos 135 dias. Os maiores teores das três poliaminas, nos calos cultivados em meio sólido, ocorreram naqueles oriundos de tratamento contendo SPD e SPM aplicadas isoladamente (T2 e T3), sendo a SPM aquela que tendeu a apresentar maiores teores, independentemente da poliamina aplicada. Resultado semelhante foi notado quando analisou-se os teores endógenos em calos nãodiferenciados e nas brotações (parte aérea) aos 165 dias de cultivo.

O material analisado oriundo do tratamento contendo PUT (T4), aos 165 dias, apresentou, em geral, a menor média de teores endógenos de poliaminas nas porções de calos intactos $(\mathrm{PUT}=10,7 ; \mathrm{SPD}=21,9 \mathrm{e}$ $\mathrm{SPM}=78,6\left(\mathrm{~g} \mathrm{~g}^{-1} \mathrm{mf}\right)$, porém foram também observados 
Tabela 2 - Teores endógenos de poliaminas, proteínas solúveis totais e atividade de peroxidases em Hemerocallis sp. submetido a tratamentos com poliaminas ( $\mathrm{T} 1=$ isento de poliaminas, $\mathrm{T} 2=10 \mu \mathrm{mol} \mathrm{g} \mathrm{mf}^{-1} \mathrm{SPD}, \mathrm{T} 3=10 \mu \mathrm{mol} \mathrm{g} \mathrm{mf}^{-1} \mathrm{SPM}, \mathrm{T} 4=10 \mu \mathrm{mol} \mathrm{g} \mathrm{mf}^{-1} \mathrm{PUT}$, T5 $=10 \mu \mathrm{mol} \mathrm{g} \mathrm{mf}^{-1} \mathrm{SPD}+10 \mu \mathrm{mol} \mathrm{g} \mathrm{mf}^{-1}$ SPM, T6 $=10 \mu \mathrm{mol} \mathrm{g} \mathrm{mf}^{-1} \mathrm{SPD}+10 \mu \mathrm{mol} \mathrm{g} \mathrm{mf}^{-1} \mathrm{PUT}, \mathrm{T} 7=10 \mu \mathrm{mol} \mathrm{g} \mathrm{mf}^{-1} \mathrm{SPM}+10 \mu \mathrm{mol} \mathrm{g} \mathrm{mf}{ }^{-1} \mathrm{PUT}, \mathrm{T} 8=10 \mu \mathrm{mol} \mathrm{g} \mathrm{mf}{ }^{-1} \mathrm{SPD}+10 \mu \mathrm{mol} \mathrm{g} \mathrm{mf}^{-1}$ $\mathrm{SPM}+10 \mu \mathrm{mol} \mathrm{g} \mathrm{mf}^{-1} \mathrm{PUT}$ ) e cultivado em meio de cultura MS por 135 dias de cultivo e em meio de cultura MS sob agitação (100rpm) por 165 dias de cultivo.

\begin{tabular}{|c|c|c|c|c|c|c|c|c|c|c|}
\hline \multirow[b]{2}{*}{ Tratamentos } & \multicolumn{8}{|c|}{135 dias de cultivo } & & \\
\hline & SPM & $1 \mathrm{mf})^{(\mu \mathrm{molg}}$ & \multicolumn{2}{|c|}{$\operatorname{SPD}\left(\mu \mathrm{mol} \mathrm{g}{ }^{-1} \mathrm{mf}\right)$} & \multicolumn{2}{|c|}{ PUT } & \multicolumn{2}{|c|}{ Proteínas } & \multicolumn{2}{|c|}{$\begin{array}{c}\text { Peroxidases } \\
\left(\mu \mathrm{mol} \mathrm{de} \mathrm{H}_{2} \mathrm{O}_{2}\right. \\
\left.\text { decomposto minuto } \mathrm{g}^{-1}\right) \\
\mathrm{mf}\end{array}$} \\
\hline T1 & \multirow{2}{*}{\multicolumn{2}{|c|}{$\begin{array}{l}- \\
359,64 b\end{array}$}} & \multicolumn{2}{|l|}{$4,31 \mathrm{~g}$} & \multicolumn{2}{|l|}{-} & \multicolumn{2}{|l|}{$0,210 \mathrm{e}$} & \multicolumn{2}{|l|}{$0,038 \mathrm{~b}$} \\
\hline $\mathrm{T} 2$ & & & $255,19 \mathrm{~b}$ & & \multicolumn{2}{|l|}{$169,89 \mathrm{~b}$} & \multicolumn{2}{|l|}{$0,417 \mathrm{a}$} & \multicolumn{2}{|l|}{$0,031 \mathrm{c}$} \\
\hline $\mathrm{T} 3$ & \multicolumn{2}{|l|}{$831,03 \mathrm{a}$} & $377,5 \mathrm{a}$ & & \multicolumn{2}{|l|}{$217,66 \mathrm{a}$} & \multicolumn{2}{|l|}{$0,197 \mathrm{f}$} & \multicolumn{2}{|l|}{$0,037 \mathrm{~b}$} \\
\hline $\mathrm{T} 4$ & \multicolumn{2}{|l|}{$47,06 \mathrm{~g}$} & $35,22 \mathrm{e}$ & & \multicolumn{2}{|l|}{$50,93 \mathrm{~g}$} & \multicolumn{2}{|l|}{$0,220 \mathrm{e}$} & \multicolumn{2}{|l|}{$0,042 \mathrm{a}$} \\
\hline T5 & \multicolumn{2}{|l|}{$130,06 \mathrm{~d}$} & $72,95 \mathrm{~d}$ & & \multicolumn{2}{|l|}{$38,51 \mathrm{~d}$} & \multicolumn{2}{|l|}{$0,323 \mathrm{~b}$} & \multicolumn{2}{|l|}{$0,026 \mathrm{e}$} \\
\hline $\mathrm{T} 6$ & \multicolumn{2}{|l|}{$156,48 \mathrm{c}$} & $73,73 \mathrm{~d}$ & & \multicolumn{2}{|l|}{$80,35 \mathrm{c}$} & $0,250 \mathrm{~d}$ & & $0,029 \mathrm{~d}$ & \\
\hline $\mathrm{T} 7$ & $98,79 \mathrm{f}$ & & $142,92 \mathrm{c}$ & & $98,17 \mathrm{f}$ & & $0,220 \mathrm{e}$ & & $0,038 \mathrm{~b}$ & \\
\hline $\mathrm{T} 8$ & $106,52 \mathrm{e}$ & & $16,09 \mathrm{f}$ & & $41,96 \mathrm{e}$ & & $0,300 \mathrm{c}$ & & $0,013 \mathrm{f}$ & \\
\hline & & & & & 5 dias de cult & & & & & \\
\hline Tratamentos & Poliaminas & $\begin{array}{c}\text { s (Calos) } \\
\text { mf }\end{array}$ & $\mu \mathrm{mol} \mathrm{g}{ }^{-1}$ & Poliaminas & $\begin{array}{c}\text { parte aérea) } \\
\text { mf }\end{array}$ & $\mu \mathrm{mol} \mathrm{g}^{-1}$ & $\begin{array}{r}\text { Proteínas } \\
\text { ptn }\end{array}$ & $\mathrm{mf})$ & $\begin{array}{l}\text { Peroxidase } \\
\mathrm{H}_{2} \mathrm{O}_{2} \text { deco }\end{array}$ & $\begin{array}{l}\quad(\mu \mathrm{mol} \mathrm{de} \\
\text { sto } \text { minuto }^{-1} \\
\text { f) }\end{array}$ \\
\hline & SPM & SPD & PUT & SPM & SPD & PUT & Calos & Parte aérea & Calos & Parte aérea \\
\hline $\mathrm{T} 1$ & $133,70 \mathrm{f}$ & $27,29 \mathrm{f}$ & $30,79 \mathrm{f}$ & $31,92 \mathrm{e}$ & $10,83 \mathrm{~d}$ & $9,20 \mathrm{f}$ & $0,20 \mathrm{ab}$ & $0,25 \mathrm{a}$ & $0,065 \mathrm{a}$ & $0,011 \mathrm{~b}$ \\
\hline $\mathrm{T} 2$ & $235,58 \mathrm{~b}$ & $14,36 \mathrm{~h}$ & $31,71 \mathrm{e}$ & - & - & - & $0,27 \mathrm{a}$ & $0,25 \mathrm{a}$ & $0,026 \mathrm{a}$ & $0,016 \mathrm{~b}$ \\
\hline $\mathrm{T} 3$ & $243,48 \mathrm{a}$ & $28,46 \mathrm{e}$ & $65,31 \mathrm{c}$ & $48,60 \mathrm{~d}$ & $18,43 \mathrm{c}$ & $13,71 \mathrm{e}$ & $0,18 \mathrm{~b}$ & $0,18 \mathrm{ab}$ & $0,074 \mathrm{a}$ & $0,342 \mathrm{a}$ \\
\hline $\mathrm{T} 4$ & $78,64 \mathrm{~h}$ & $21,97 \mathrm{~g}$ & $10,78 \mathrm{~g}$ & $88,94 \mathrm{c}$ & $37,84 \mathrm{~b}$ & $21,87 \mathrm{~d}$ & $0,18 \mathrm{~b}$ & $0,14 \mathrm{~b}$ & 0,067 a & $0,118 \mathrm{ab}$ \\
\hline $\mathrm{T} 5$ & $149,09 \mathrm{e}$ & 70,49 a & 89,56 a & - & - & - & $0,15 \mathrm{~b}$ & $0,19 a b$ & $0,235 \mathrm{a}$ & $0,082 \mathrm{ab}$ \\
\hline T6 & $130,75 \mathrm{~g}$ & $35,59 \mathrm{~d}$ & $72,41 \mathrm{~b}$ & $146,50 \mathrm{a}$ & $43,35 \mathrm{a}$ & $22,47 \mathrm{e}$ & $0,16 \mathrm{~b}$ & $0,18 \mathrm{ab}$ & $0,104 \mathrm{a}$ & $0,088 \mathrm{ab}$ \\
\hline $\mathrm{T} 7$ & $202,75 \mathrm{c}$ & $47,70 \mathrm{~b}$ & $56,96 \mathrm{~d}$ & $92,23 \mathrm{~b}$ & $43,58 \mathrm{a}$ & $27,60 \mathrm{a}$ & $0,13 \mathrm{~b}$ & $0,13 \mathrm{~b}$ & $0,132 \mathrm{a}$ & $0,122 \mathrm{ab}$ \\
\hline $\mathrm{T} 8$ & $165,39 d$ & $38,33 \mathrm{c}$ & 89,59 a & - & - & $23,58 \mathrm{~b}$ & $0,15 \mathrm{~b}$ & $0,14 \mathrm{~b}$ & 0,017 a & $0,075 \mathrm{ab}$ \\
\hline
\end{tabular}

Letras que se diferenciam na vertical indicam diferença significativa entre as médias pelo teste Tukey $5 \%$ ( $\mathrm{N}=10)$.

os maiores números de brotos e raízes diferenciadas. Por outro lado, nas porções de calos intactos, oriundos do tratamento onde se aplicou exogenamente SPD e/ ou SPM isoladamente (T2 e T3), observou-se, em geral, os maiores teores de SPM, enquanto que, na parte aérea regenerada, os teores foram muito baixos nos tratamentos contendo SPD isolada (T2) ou em combinação com SPM (T5). Quando as duas poliaminas foram combinadas com PUT (T6, T7 e T8), ocorreu maior formação de microplantas, mostrando a possível necessidade das três aminas nesta fase, enquanto que uma possível relação inversa pode ser necessária para a regeneração em Hemerocallis. Nas plantas regeneradas, assim como nos calos intactos, evidenciase a predominância de SPM endógena, o que pode ser devido ao metabolismo das enzimas poliaminas sintetase e S-adenosilmetionina sintetase, resultando num acúmulo de SPM, principalmente (MARTINTANGUY \& CARRE, 1993). Alto teor de SPM também ocorreu nos tratamentos contendo SPD (T2, T5, T6 e T8), evidenciando uma possível tendência de formação de SPM em Hemerocallis.

As partes aéreas regeneradas de calos com alta taxa de necrose, oriundas dos tratamentos contendo SPD e SPM (T2, T3 e T5), apresentaram traços de poliaminas endógenas, enquanto que o tratamento que combinava SPD e PUT (T6), com taxa relativamente alta de necrose, mostrou alto teor de poliaminas, principalmente de SPM, indicando que a PUT possívelmente seja essencial para a regeneração.

A adição de PUT isolada (T4) no meio de cultivo de Hemerocallis, mesmo não mostrando diferença significativa, foi eficiente na indução de brotos, altura e porcentagem de microplantas nos calos, após 135 dias em meio de cultivo semi-sólido. Quando os calos foram transferidos para meio líquido, a combinação das três poliaminas (T8) foi eficiente na indução de microplantas (165 dias de cultivo) em relação à testemunha. Segundo DEBIASI (2000), em geral, o comportamento em relação à média proliferativa e o tamanho dos brotos in vitro é inversamente proporcional, ou seja, quanto maior o número de brotos formados em um explante, menor será o seu tamanho. Esse fato não foi observado quando se aplicou as três poliaminas (T8) no meio de cultura e os valores encontrados foram inferiores aos observados quando se aplicou somente PUT (T4) exógena. DAVIS \& OLSON (1994) encontraram pequena eficiência no uso de 
concentrações menores que $5 \mathrm{mM}$ de PUT exógena na formação de raízes ou brotos em Euphorbia esula L., sendo que em certos meios utilizados, como B5, essa diamina inibiu completamente a organogênese. Por outro lado, SAIPRASAD et al. (2004) verificaram que PUT, na concentração de $0,4 \mathrm{mM}$, induziu maior número de protocormos durante o cultivo in vitro da orquídea Dendrobium "Sonia", assim como em Cichorium intybus, onde a aplicação desta poliamina (40mM) promoveu maior número e comprimento de brotos, enquanto que concentração 10 vezes maior inibiu-os (BAIS et al., 2000), levantando a idéia de que a concentração ideal para indução de brotos ou raízes ainda necessita ser mais estudada. BAGNI \& SERAFINI-FRACASSINI (1985) relatam que as poliaminas exógenas seriam meras fontes de nitrogênio para as plantas, em contraste com relatos de BAIS et al. (2000), que afirmam que as poliaminas têm um papel fisiológico no crescimento e na produção de metabólitos secundários, não sendo assim apenas fontes do nutriente, tendo papel regulador em diversos eventos (EGEA-CORTINES \& MIZRAHI, 1991; LEE, 1997).

SPD isolada (T2) ou combinada com SPM (T5) inibiu a formação de raízes nos calos com 135 dias. A inibição do crescimento de raiz por SPD já foi descrita anteriormente em Arabdopsis por TASSONI et al. (2000), quando usaram concentrações acima de $0,8 \mathrm{mM}$.

$\mathrm{O}$ uso exógeno de SPD isolada (T2) ou combinada com SPM (T5) ou PUT (T6), nos calos mantidos em meio líquido por 30 dias (165 dias), forneceu material com alta porcentagem de oxidação. Observou-se relação negativa dos calos crescidos em meio contendo SPD, os quais apresentaram alta porcentagem de tecido oxidado (escuro/necrosado), com número e altura dos brotos formados, além de ausência de raízes, enquanto que a presença da PUT atenuou esse efeito. TANG et al. (2004) observaram em calos de Pinus virginiana Mill. que as brotações e raízes oriundas de calos oxidados apresentaram má formação e baixa taxa de sobrevivência quando aclimatadas.

A oxidação é um fenômeno observado em calos de algumas espécies vegetais e pode causar a morte da célula. É um estresse oxidativo, o qual tem sido atribuído a diversos agentes causais, e as poliaminas, principalmente PUT e SPD, não somente atuam como colaboradoras na recuperação da oxidação, mas também melhoraram o crescimento, a formação de brotos e o enraizamento em pinus (TANG et al., 2004). Outros trabalhos (PAPADAKIS \& ROUBELAKISANGELAKIS, 2005) atribuem à PUT um efeito protetor contra células programadas para morte (CPM), o qual seria consistente com o efeito estimulante no crescimento, e os aumentos dos níveis de PUT seriam devidos ao direcionamento para uma via proliferativa.

A combinação de SPD e SPM (T5) não induziu brotações aos 135 dias, mas a porcentagem de calos obtida foi máxima (Tabela 1). Aos 165 dias, a mesma tendência é notada, assim como nas plantas cultivadas em meio contendo as poliaminas isoladas. Os teores de poliaminas nos tratamentos contendo SPD (T2) e a sua combinação com SPM (T5) foram muito baixos nas plantas regeneradas, sendo que altos teores, principalmente de SPD, ocorrem nos tratamentos contendo as poliaminas exógenas aplicadas isoladamente (Tabela 2). Este resultado poderia ser explicado pela ação metabólica dessas duas poliaminas em relação à divisão e ao crescimento de células, formando, nesse caso, calos. A correlação direta entre teores de poliaminas e síntese de DNA foi encontrada em Helianthus tuberosus e em células de beterraba açucareira (FOWLER et al., 1996; THEISS et al., 2002). Em células BY-2 de tabaco, os níveis de SPD e SPM aumentaram, atingindo um máximo no início da fase exponencial, enquanto que os teores de PUT mostraram diminuição durante a lag-fase, aumentando até o final da fase exponencial (GEMPERLOVÁ et al., 2005). Neste caso, em Hemerocallis, PUT exógena seria recomendada para multiplicação e regeneração enquanto que SPD e SPM para obtenção de calos.

Altas taxas de células com hiperhidricidade foram encontradas em meios contendo SPD exógena, combinada ou não. Os teores de poliaminas verificados nos tratamentos que induziram maior taxa de hiperhidricidade foram maiores nos tratamentos contendo SPD exógena, combinada ou isolada com outras poliaminas. A aplicação isolada induziu maiores teores das poliaminas analisadas. Esses resultados são interessantes, já que FRANCK et al. (2004) relatam que um pico na produção de etileno foi observado em brotos de Prunus avium submetidos a condições de hiperhidricidade, um fenômeno atribuído previamente às condições de cultivo.

As poliaminas apresentam atividade antioxidante por protegerem os ácidos nucléicos contra desnaturação enzimática ou oxidativa e por previnirem contra peroxidação de lipídeos (BOUCHEREAU et al., 1999). Neste trabalho, foi verificado maior teor das três poliaminas principalmente nos meios contendo SPM, os quais apresentaram maior taxa de células com hiperhidricidade, provavelmente, neste caso, essas substâncias estariam agindo como um possível protetor das células, como sugerido por alguns autores (PIQUERAS et al., 2002). Em alguns casos, como no trabalho com folhas de Dianthus caaryophyllus, os teores de poliaminas totais não apresentaram diferença entre aquelas com hiperhidricidade ou não, porém apresentaram aumento nas plantas que mostraram reversão do sintoma; por outro lado, o teor de PUT foi maior naquelas sem o sintoma e este efeito pode ser atribuído a injúrias oxidativas (PIQUERAS et al., 2002). Geralmente, aumento nos teores de PUT tem sido atribuído a diferentes tipos de estresse, o que indicaria que esses tecidos estariam sofrendo algum tipo de dano metabólico.

Os teores endógenos de proteínas solúveis totais e atividades das peroxidases são apresentados 
na tabela 2. A atividade da peroxidase em calos cultivados durante 135 dias foi maior em meio contendo PUT aplicada isoladamente (T4). Não foi observada oxidação nos tecidos durante o cultivo nesta época, mas ocorreu grande porcentagem de hiperhidricidade no material estudado, sendo a maior taxa verificada nos tratamentos com SPM (T3, T5, T7, T8) e no controle.

Em todos os tratamentos, a atividade da enzima foi menor em relação aos resultados encontrados nos calos que não apresentaram regeneração (165 dias). As avaliações da atividade das peroxidases naquelas porções de calos intactos (sem regeneração) revelam semelhança entre os tratamentos e nota-se que calos não-regenerados cultivados em meio contendo a combinação de SPD e SPM (T5) apresentaram maior atividade e maior porcentagem de tecido oxidado, enquanto as três poliaminas (T8) induziram resultados contrários, isto é, baixa atividade. Por outro lado, a atividade da peroxidase na parte aérea de Hemerocallis foi maior em plantas cultivadas em meio contendo SPM (T3), o que nos leva a supor que, em calos, essa poliamina aplicada exogenamente pode mostrar efeito positivo quanto ao papel antioxidante, fato este que não se aplica quando se estuda a parte aérea, pois, provavelmente, a peroxidase estaria relacionada com a atividade morfogênica da planta. Nesta época de avaliação, nas condições de cultivo em meio líquido, poucos tratamentos induziram baixas taxas de hiperhidricidade comparadas com a época anterior.

A atividade da peroxidase (Tabela 2) encontrada nos calos aos 135 dias pode ter sido devida à hiperhidricidade encontrada, principalmente em meio contendo SPM (T3). PIQUERAS et al. (2002) descrevem aumento na atividade da peroxidase em folhas de Dianthus caryophyllus como conseqüência da hiperhidricidade, devido a danos oxidativos e peroxidação de lipídeos. Possivelmente, parte do material analisado neste trabalho estaria no estado hiperhídrico, já que não houve separação no momento da análise, mostrando como resposta bioquímica aumento na atividade de enzimas oxidativas, como a peroxidase.

Além da hiperhidricidade, outros fatores podem promover alterações na atividade da peroxidase, como o escurecimento do tecido (oxidação), que geralmente reduz o crescimento de calos e inibe a formação de brotos (TANG \& NEWTON, 2005). LAUKKANEN et al. (1999 e 2000) relatam que o tecido oxidado está associado com o aumento de enzimas como peroxidase e polifenoloxidase, bem como à desorganização e eventual morte celular. A oxidação é um dos maiores impedimentos do cultivo in vitro de plantas, causando grande perda. Embora a capacidade de oxidação seja um fenômeno complicado e regulado por diversos fatores, enzimas como a peroxidase poderiam ter um efeito indireto. Tem sido sugerido que alta atividade da peroxidase e polifenoloxidase poderiam reduzir o crescimento e cessar o desenvolvimento embriogênico (LAUKKANEN et al., 1999). Em Rannunculus asiaticus, calos não-diferenciados apresentaram maior teor de polímeros fenólicos e elevada atividade da peroxidase (BERUTO et al., 1996).

O tratamento contendo SPD e SPM (T5) induziu a maior porcentagem de tecido oxidado e, por conseqüência, necrose e morte, e este tratamento também apresentou a maior atividade da peroxidase aos 165 dias. TANG et al. (2004) verificaram que PUT ou SPD, aplicadas exogenamente, mostraram efeito positivo quanto à diminuição da oxidação em calos de Pinus virgininana Mill, promovendo também maior crescimento dos calos, brotação e raiz. Em Fraxinus angustifólia, a aplicação de poliaminas, tais como PUT e SPD, na fase de indução, aumentou o enraizamento, enquanto que na fase de expressão houve baixa concentração de poliaminas e aumento na atividade da peroxidase (TONON et al., 2001). Pela literatura, as poliaminas têm sido descritas como possíveis protetoras contra danos oxidativos, diminuindo o escurecimento, sendo que a peroxidase poderia ser utilizada como medida da ação das poliaminas. TANG et al. (2004) demonstraram que PUT e SPD exógenas foram mais efetivas contra os danos oxidativos, promovendo baixa atividade da enzima. Resultados diferentes são encontrados neste trabalho, em que SPM em calos não-regenerados (poliamina predominante em Hemerocallis) pode ter agido como protetora contra o estresse oxidativo, diminuindo o escurecimento e, quando associada com PUT, a ação pode ter sido intensificada, já que não foi observada oxidação nestes tratamentos. KITADA et al. (1979) foram os pioneiros em sugerir que as poliaminas agem como agentes antioxidantes e relataram que SPM foi mais efetiva na inibição da peroxidacao de lipídeos em fígado de ratos, por se ligar às cargas negativas na superfície da membrana. Por outro lado, a atividade da peroxidase na parte aérea de Hemerocallis foi maior em plantas cultivadas em meio contendo SPM, sugerindo que, em calos, essa poliamina, aplicada exogenamente, pode mostrar efeito positivo quanto ao papel antioxidante, fato este que não se aplica quando se estuda a parte aérea.

\section{CONCLUSÃO}

As poliaminas putrescina e/ou espermidina induzem brotações, e a combinação das três poliaminas estudadas (putrescina, espermidina e espermina) induz a formação de microplantas em Hemerocallis. A combinaçao de espermidina e espermina induz necrose nos tecidos, e SPM exógena atuou como antioxidante em calos.

\section{AGRADECIMENTOS}

Os autores agradecem ao suporte financeiro do Conselho Nacional de Desenvolvimento Científico e 
Tecnológico (CNPq) e da Fundação para o Desenvolvimento da UNESP (FUNDUNESP).

\section{REFERÊNCIAS}

BAGNI, N.; SERAFINI-FRACASSINI, D. Involvement of polyamines in the mechanism of break of dormancy in Helianthus tuberosus. Bulletim Society Bot. France Actual Botanical, n.132, p.119-125, 1985.

BAIS, H.P. et al. Putrescine and silver nitrate influence shoot multiplication, in vitro flowering and endogenous titers of polyamines in Cichorium intybus L. cv. Lucknow local. Journal of Plant Growth Regulation, v.19, p.238-248, 2000 .

BRADFORD, M. A rapid and sensitive method for the quantitation of microgram quantities of protein utilizing the principle of protein-dye binding". Analitical Biochemistry, v.72, p.248-254, 1976.

BERUTO, M. et al. Callus growth and somatic embryogenesis in thalamus tissue of Ranunculus asiaticus L. cultivated in vitro: Cytokinin effect and phenol metabolism. In vitro Cellular and Developmental Biology-Plant, v.32, p.154160, 1996.

BOUCHEREAU, A. et al. Polyamines and environmental challenges: recent development. Plant Science, v.140, p.103$125,1999$.

DAVIS, D.G.; OLSON, P.A. Effects of putrescine and inhibitors of putrescine biosynthesis ono rganogeneses in Euphorbia esula L. In vitro Cellular and Developmental Biology-Plant, v.30P, p.124-130, 1994.

DEBIASI, C. Efeitos de antiauxinas sobre a dominância apical em gemas de bananeira in vitro cvs. Grand naine (AAA), Nanicão (AAA) e Enxerto (AAB). 2000. $100 \mathrm{f}$. Dissertação (Mestrado em Recursos Genéticos Vegetais) - Curso de Mestrado em Recursos Genéticos Vegetais, Universidade Federal de Santa Catarina.

EGEA-CORTINES, M.; MIZRAHI, Y. Polyamines in cell division, fruit set and development and seed germination. In: SLOCUM, R.D.; FLORES, H.E. (Eds). Biochemistry and physiology of polyamines in plants. Boca Raton, Florida: CRC, 1991. p.143-158.

FLORES, H.E.; GALSTON, A.W. Analysis of polyamines in higher plant by high performance liquid chromatography. Plant Physiology, v.69, n.3, p.701-706, 1982.

FOWLER, M.R. et al. Polyamine metabolism and gene regulation during the transition of autonomous sugar beet cells in suspension culture from quiescence to division. Physiologia Plantarum, v.98, p.439-446, 1996

FRANCK, T. et al. Hyperhydricity of Prunus avium shoots cultured on gelrite: a controlled stress response. Plant Physiology and Biochemistry, v.42, p.519-527, 2004.

GEMPERLOVÁ L.A.B. et al. Polyamine metabolism during the growth cycle of tobacco BY-2 cells. Plant Physiology and Biochemistry, v.43, p.375-381, 2005.

KITADA, M.K. et al. Inhibition by polyamines of lipid peroxide formation in rat liver microsomes. Biochemical Biophysical Research Communication, v.87, p.388-394,1979.

LAUKKANEN, H. et al. Tissue browning of in vitro cultures of Scots pine: role of peroxidase and polyphenol oxidase. Physiologia Plantarum, v.106, p.337-343, 1999.
LAUKKANEN, H. et al. Changes in cellular structures and enzymatic activities during browning of Scots pine callus derived from mature buds. Tree Physiology, v.20, p.467475,2000 .

LEE, T.M. Polyamine regulation of growth and chilling tolerance of rice (Oryza sativa L.) roots cultured in vitro. Plant Science, v.122, p.111-117, 1997.

LIMA, G.P.P et al. Poliaminas e atividade da peroxidase em feijão (Phaseolus vulgaris L.) cultivado sob estresse salino. Scientia Agricola, v.56, p.21-25, 1999.

LIMA, G.P.P. et al. Polyamines contents in some foods from Brazilian population basic diet. Ciência Rural, v.36, p.12941298, 2006.

LOVAAS, E. Antioxidative and metal-chelating effects of polyamines. Advance in Pharmacology, v.38, p.119-149, 1997.

MARTIN-TANGUY, J.; CARRE, M. Polyamines in grapevine microcuttings cultivated in vitro. Effects of amines and inhibitors as polyamine biosynthesis on polyamine leaves and microcuttings growth and development. Plant Growth Regulation, v.13, p.269-280, 1993.

PAPADAKIS, A.K.; ROUBELAKIS-ANGELAKIS, K.A. Polyamines inhibit NADPH oxidase-mediated superoxide generation and putrescine prevents programmed cell death syndrome induced by the polyamine oxidase-generated hydrogen peroxide. Planta, v.220, p.826-837, 2005.

PIQUERAS, A et al. Polyamines and hyperhydricity in micropropagated carnation plants. Plant Science, v.162, p.671-678, 2002.

RUGINI, E. et al. Endogenous polyamine and root morphonenesis variation under different treatment in cutting and in vitro explants of olive. Acta Horticulturae, v.300, p.225-232, 1992 .

SAIPRASAD, G.V.S. et al. Effect of various polyamines on production of protocorm-like bodies in orchid-Dendrobium 'Sonia'. Scientia Horticulturae, v.100, p.161-168, 2004.

TANG, W.; NEWTON, R.J. Polyamines reduce salt-induced oxidative damage by increasing the activities of antioxidant enzymes and decreasing lipid peroxidation in Virginia pine. Plant Growth Regulation, v.46, p.31-43, 2005.

TANG, W. et al. Exogenously added polyamines recover browning tissues into normal callus cultures and improve plant regeneration in pine. Physiologia Plantarum, v.122, p.386$395,2004$.

TASSONI, A. et al. Polyamine content and metabolism in Arabidopsis thaliana and effect of spermidine on plant development. Plant Physiology and Biochemistry, v.385, p.383-393, 2000.

THEISS, C. et al. Regulation by polyamines of ornithine decarboxylase activity and cell division in the unicellular green alga Chlamydomonas reinhardtii. Plant Physiology, v.128, p.1470-1479, 2002.

TONON, G. et al. Changes in polyamines, auxins and peroxidase activity during in vitro rooting of Fraxinus angustifolia shoots: an auxin-independent rooting model. Tree Physiology, v.21, p.655-663, 2001.

YADAV, J.S.; RAJAM, M.V. Spatial distribution of free and conjugated polyamines in leaves of Solanum tuberosum associated whit differential morphogenetic capacity: efficient somatic embryogenesis with putrescine. Journal of Experimental Botany, v.48, n.313, p.1537-1545, 1997. 